\title{
The Applicability of (STEAM) in Pre-university Education from the Perspective of Science and Mathematics Teachers at Najran
}

\author{
Abdulaziz Almalki", Yahya Faqihi \\ Department of Curriculum \& Instruction, College of Education, Najran University, Saudi Arabia
}

Received December 13, 2020; Revised January 11, 2021; Accepted February 18, 2021

\section{Cite This Paper in the following Citation Styles}

(a): [1] Abdulaziz Almalki, Yahya Faqihi, "The Applicability of (STEAM) in Pre-university Education from the Perspective of Science and Mathematics Teachers at Najran," Universal Journal of Educational Research, Vol. 9, No. 2, pp. 362 - 372, 2021. DOI: 10.13189/ujer.2021.090212.

(b): Abdulaziz Almalki, Yahya Faqihi (2021). The Applicability of (STEAM) in Pre-university Education from the Perspective of Science and Mathematics Teachers at Najran. Universal Journal of Educational Research, 9(2), 362 - 372. DOI: 10.13189/ujer.2021.090212.

Copyright $\bigcirc 2021$ by authors, all rights reserved. Authors agree that this article remains permanently open access under the terms of the Creative Commons Attribution License 4.0 International License

\begin{abstract}
Science, Technology, Engineering, Art and Mathematics STEAM education not only promotes students learning, but also has a significant effect on their thinking, creativity, and character. In this study, the researchers investigated the applicability of (STEAM) public education from the perspective of science and mathematics school teachers at Najran city, and the impact of gender, specialization, school level and teaching experience variables on teachers' perceptions and their self-efficacy towards applying this approach. A scale of self-efficacy of math and science teachers on STEAM was applied to 221 of Najran city school teachers in the Southern region of Saudi Arabia. An internal consistency check and validity tests were performed to ensure the reliability and validity of the measure. The results indicated that the suggested methods for employing (STEAM) in the pre-university education reported high preference levels by teachers. Furthermore, differences exist on the STEAM practices and self-efficacy between the participants characteristics (gender, specialization, education level and work experience). Hence, although literature offers some information regarding teacher's perception and their STEAM practices, much remains to be unknown. There is a gap in terms of improving teachers' belief towards STEAM education and its practices. Results suggest that STEAM practices can be part of the education curriculum.
\end{abstract}

Keywords STEAM, Pre-university Education, Mathematics, Science

\section{Introduction}

The integration between knowledge and skills provides appropriate and effective solutions to many problems encountered upon teaching science and mathematics. In this response, one of the recent trends used to handle these problems in education field is (STEAM) education, which expresses the integration between the fields of Science, Technology, Engineering and Mathematics, and to which Arts has been added as a new dimension represented by the "A" in (STEAM) so as - to achieve on the one hand - a further effectiveness through the integration of objectivity, logicality and analysis distinguishing (STEAM) approach, with the subjectivity, intuition, sensory and uniqueness characterizing Arts on the other hand. Therefore, an integration between science and arts would be established, i.e. science provides a methodological tool for Arts, and Arts - in turn - provides an innovative model in developing Science. The importance of STEAM education stems from instructing learners to think out of the box and employing the available tools creatively. It also urges them to ask questions, to keep them engaged and to promote their creativity and social empowerment in Science, Technology, Mathematics, Arts and Engineering [1]. The addition of Arts into STEAM-education fields is of great importance for developing creativity and 
innovation among students; preparing them to exploit opportunities when encountering the serious challenges of our time; and expand their interest to include several processes, skills and knowledge [2]. Accordingly, this approach is concerned with creating an appropriate learning environment for students to help them enjoy the workshops of STEAM, in a way reinforces their self-efficacy, self-reliance and sense of achievement through the use of practice, application of comprehensive and interrelated concepts, and furthering their understanding about the main ideas of different scientific fields.

\subsection{Background}

Teaching students through (STEAM) education encourages them to connect (STEAM) fields and the artistic disciplines. It also helps improve their creativity related to science by highlighting its interference with Arts [3]. In addition, STEAM education is considered effective in enhancing the achievement of scientific and physical concepts among students compared to their colleagues who study using traditional methods [4] (STEAM) education also has a key role in improving the functional geometric awareness among elementary school students and a positive impact on their attitudes toward engineering, technology, and future career choices [5]. (STEAM) education contributes to enhancing learners' level of thinking competence by providing them with a sense of conscious control over their thinking, which allows them to practice planning, monitoring, organizing, deducing, and rebuilding as they perform a task or complete specific projects or plans [6]. Moreover, [3] asserts that (STEAM) education opens up aspects of creative thinking to students more than ordinary education; Whereas the learner begins with noticing phenomena, re-imagining them visually and mentally, and then transforming these ideas into algorithms expressed digitally to be used later in building important tools and devices, starting from home appliances to space applications. This trend also encourages learners to create solutions and invent devices to overcome and solve certain problems, enhance their communication skills, achieving a more realistic thinking about life's problems, and effectively engage in teamwork.

In the educational field, the implementation and activation of modern educational trends require careful consideration of two important factors: teachers' perceptions of this trend, and their impressions about their ability to apply it within the process of teaching in line with its scientific requirements and procedures; i.e. an individual's self-efficacy (effectiveness) that has been defined as a set of judgments expressing an individual's beliefs about his ability to carry out certain behaviors, and his flexibility in dealing with difficult situations and encountering difficulties [7]. And as a theoretical formation suggested by (Bandura) -The founder of Social Cognitive Learning Theory- it is the cognitive mechanism that forms the basis for changing behavior. It is therefore a judgment an individual makes about his/her abilities to organize and perform a set of actions required to achieve certain patterns of performance. Taking into consideration of the curricula of science and mathematics developed in $\mathrm{KSA}$, we find that their infrastructure is based on McGraw Hill Global Series. Therefore, they promote the idea of integration between knowledge fields, as they contain several educational activities with the aim of linking the fields of science, mathematics and others [8]. However, according to the researchers' experience and acquaintance with the nature of teaching science and mathematics, it is believed that the activities which are not implemented at the desired level, due to several obstacles, the most important of which is the prevailing thought among teachers that have strengthened the separation between science and mathematics, as well as between science, mathematics and other knowledge-based fields, such as engineering, technology and arts that constitute the fields (STEAM) education. Another obstacle is that teachers, during their training programs for the teaching profession in the Faculties of Education, were not qualified to address this linkage and integration as this would necessarily lead to problems while applying the integration of science and mathematics teaching.

Since (STEAM) is one of the latest educational trends affecting curriculum structure, its impact extends to include teaching performance and teachers' perceptions about it. Their self-efficacy related to it may represent a source of support or resistance to any efforts related to its application in pre-university education. Therefore, the researchers found that it is necessary to carry out a scientific study revealing the applicability of (STEAM) from Science and Mathematics teachers' perceptions, as there is a scarcity of Arab and local studies addressing this aspect. Thus, the current study asserts the importance of developing science and mathematics curricula in line with the requirements of the integrative approach (STEAM), as well as teachers' acceptance of its application in their schools by expressing their perceptions regarding its nature and the possibility of its application. Furthermore, the current study seeks to enrich the previous literature interested in STEAM education.

Accordingly, it can be said that teachers' perceptions and self-efficacy represent either a source of support or resistance to any reform efforts or development programs in the educational field. With respect to teachers' perceptions about integration, studies indicate that many teachers may have negative attitudes towards integration, due to its improper and incomplete application by the teachers who practiced it, as these studies attribute this failure to the fact that programs of training science and mathematics teachers have given students the impression that science and mathematics and other fields materials 
are separate entities [9];[10]. Furthermore, the educational system in school has strengthened this belief, so we may find a further separation between teaching fields of knowledge. As a result, teachers sometimes do not realize the common goals and applications of science and mathematics as well as other fields of knowledge, and hence the difficulty exists in integrating common concepts and information in different fields. This caused them to prefer the traditional ways of teaching, i.e. to present information and concepts of each subject separately.

\subsection{Purpose of the Study}

Since teachers' acceptance of recent trends in the field of education are directly affected by their perceptions of the nature of teaching, and the fact that all of this may be affected by some variables, the current study aims to investigate the applicability of (STEAM) public education from science and mathematics teachers' perceptions at Najran city. Additionally, it reveals the impact of gender, specialization, school level and teaching experience variables on teachers' perceptions and their self-efficacy towards applying this approach.

\subsection{Questions of the Study}

Accordingly, the study's main question is what is the applicability level of (STEAM) in pre-university education from science and mathematics teachers' perceptions at Najran, KSA? Form this main question, the following sub-questions are presented:

1. What are the preferred methods for employing (STEAM) in pre-university education from science and mathematics teachers' perceptions at Najran city?

2. What is the level of self-efficacy of science and mathematics teachers at Najran towards teaching using (STEAM) from their perceptions?

3. Are there any statistically significant differences in the responses of science and mathematics teachers at Najran regarding the application of the (STEAM) when it comes to gender, specialization, school level and teaching experience?

\section{Theoretical Framework}

In 2007, the term "STEAM" appeared as a new educational landmark including the fields of science, technology, engineering, arts and mathematics, in response to students' increased interest in these fields [11]. It is an interdisciplinary learning process that increases diverse participation in several fields [11]. It is widely used as a subsystem to link these separate approaches using applications and processes contributing to the creation of integrated knowledge [12]. STEAM education integrates science, technology, engineering, arts and mathematics with the aim of improving student engagement and knowledge, as well as improving their innovation and problem-solving skills [13]. It also seeks to improve students' skills in communication, teamwork and adaptability [14]. As a model, STEAM education may go even further reflecting education's viewpoint with an emphasis on creative and diversified teaching and learning in the real world, as well as the emphasis on problem-based or project-based learning [15]. It should be noted that the term STEAM started with only four fields termed as STEAM, before the addition of Arts [16]. STEAM education also assumes that technology partially facilitates the process of problem-solving. The main difference between STEM and STEAM is this interdisciplinary approach in which real problems are explored and students have the opportunity to have a better understanding of how things are relating to each other [12]. The inclusion of Arts within the acronym STEAM led to a great difference and conflict of views. Some scholars considered that Arts represents art education that is concerned with visual arts (drawing, photography, sculpture, design, and media art) [11]. Other scholars consider Arts as the visual and performing arts, such as digital and aesthetic media, in addition to humanities [16].

$\mathrm{V}$ education aims to develop competent students who are capable of working in a high-tech environment using several approaches [11]. STEAM-based curricula increase motivation, participation and effective learning in several fields. These curricula also lead to a further diversity of students interested in pursuing different professions in support of these fields [17]. They also address the issue of attracting and retaining a diverse workforce in science, technology, engineering, arts and mathematics. Therefore, the way we teach our students must be reformulated, so that we can attract and retain alternative perspectives that would help us in solving world's most urgent issues [11]. Using STEAM education in teaching is also known as interdisciplinary teaching that helps students explore learning content through posing a problem using multiple inquiry processes that naturally link approaches through the problem to be solved [12]. STEAM education activities provide students with a natural environment for collaboration and communication. For instance, these activities allow them to discuss various strategies and proposals of a simplified engineering design [18]. In addition, the use of STEAM education requires teachers training to improve their potentials, and then have an adequate knowledge and skill framework in order to facilitate the integration of STEAM in different educational contexts through the provision of guidelines ensuring the appropriate practices in different contexts [19]. Furthermore, $\mathrm{V}$ was introduced to improve individuals $21^{\text {st }}$-century skills such as entrepreneurship, innovation, creative thinking, decision-making and problem solving [26], [29], and to increase individuals' interest and awareness [18]. Although, literature basically presented STEAM in a positive view, some disadvantages 
were highlighted including social and educational justice [28]; [27], as well as budget planning and economic infrastructure which can prevent STEAM education from reaching all segments of society [29], in addition to poor content delivery and inadequate methods of assessment [25].

Through the use of STEAM education, it is possible to respond adequately and effectively to current challenges and future ones. As time passes, more professions will be at risk, as they will disappear one by one. Moreover, knowledge and skills associated with those professions will disappear. Thus, there is a need to develop and integrate different courses into STEAM education in order to keep pace with the ongoing developments [20]. Although it is evident that the current study is similar to previous ones in addressing the integrative approach between science, technology, engineering and mathematics (STEM- STEAM), the importance of the current study stems from addressing the preferred methods for employing (STEAM) in education from the perspective of science and mathematics teachers; their self-competence towards using (STEAM) education in teaching; and their responses regarding the application of (STEAM) based on a set of demographic variables: gender, specialization, educational rank, and teaching experience. The researchers have benefited from these studies in enriching the study's theoretical literature, procedures, developing its instrument, in addition to the way of analyzing and discussing its findings.

\section{Methodology}

This study primarily aims to investigate the applicability of (STEAM) public education from the perspective of science and mathematics teachers at Najran city. It also reveals the impact of gender, specialization, school level and teaching experience variables on teachers' perceptions and their self-efficacy towards applying this approach. Therefore, the study adopts a descriptive survey approach, using quantitative tools to achieve the study objective. Survey is suitable in gathering information on the participants belief and attitudes and large sample size [30];[31].

\subsection{Sample}

A total of 221 participants who are teaching Math and Science in Najran City took part in the present study. The participants were identified as Math and Science teachers and were selected from Najran city in the South Saudi Arabia during the second semester of the 2018/2019 academic year. The participants were 136 males' teachers and 85 females.

\subsection{Measurement}

The measurement used to gauge self-efficacy of math and science teachers on STEAM which was developed by the researchers. The measure consists of 17 items and was divided into two factors, 1) investing STEAM approach which consisted of 7 items and 2) self-efficacy with 10 items. Specifically, the measure comprised of 17 questions, whose answers are measured on a 5-point Likert scale, ranging from 1 (strongly disagree) to 5 (strongly agree). In order to identify the self-efficacy level, the measure was divided into four levels which are: 1-1.80 (low); 1.81-2.60 (moderate); 2.61-3.40 high; and 4.20-5.0 very high. However, the measure was validated by a group of experts and test-retest was conducted and achieved the recommended values. In addition, overall Cronbach' Alpha reliability of the measure achieved the suggested value of 0.79 .

\subsection{Data Analysis}

The questions of the study required respondents to indicate the level of their views on the proposed variables, and their responses were then analyzed by using several techniques such as descriptive statistics, t-test and One-Way ANOVA.

\section{Results}

Results of the $1^{\text {st }}$ question: What are the preferred methods for employing (STEAM) in pre-university education from the perspective of science and mathematics teachers at Najran city? To answer this question, means and standard deviations for the preferred methods for employing (STEAM) from teachers' perceptions were calculated, and the result showed that the suggested methods for employing (STEAM) in the pre-university education reported high preferences levels by teachers. The total construct reported high preference level $(\mathrm{M}=4.01, \mathrm{SD}=0.69)$. At the level of items, item (7) stating: "Inclusion of (V) as enrichment activities in mathematics and science curricula" ranked first $(\mathrm{M}=4.12$, Std. Devi $=0.87$ ) with a high level. This can be attributed to the fact that teachers are aware of the importance of the enrichment activities in teaching mathematics and science, as they have a positive effect on the desired learning outcomes. Item (2) "Including (STEAM) curricula in teacher's preparation programs" ranked second $(\mathrm{M}=4.09$, Std. Devi $=0.96$ ) with a high level. This result can be attributed to the fact that teachers realize the importance of the preparation programs in education reform as the quality of education is related to the quality of teachers and their ability to keep pace with the future and the modern educational developments, including the use of integrative approach (STEAM) in education. Item (4) "Including (STEAM) as a learning material in Master and PhD programs" ranked third $(\mathrm{M}=4.08$, Std. Devi $=0.93)$ with a high level. This can be attributed to the teachers' awareness of the importance of Master and $\mathrm{PhD}$ programs 
offered by Saudi universities and their trust in their role in preparing teachers before and during service, which conforms with the modern educational developments, including employing (STEAM) in education, specifically in teaching science and mathematics.

Item (1) "Establishing schools dedicated to teach students according to (STEAM) curricula" ranked last (M $=3.77$, Std. Devi $=1.08$ ) with a high level. However, there is a need for a big financial support, in addition to the efforts of various governmental and private sectors to implement this idea; and to study the similar experiences in Arab countries to find out the extent of their success. It can also be noted that the other items concerned with the preferred methods in employing (STEAM) got high levels. One of those methods was rebuilding science and mathematics curricula according to the (STEAM), using it as an optional extra-curricular activity for the gifted and outstanding students in schools and centers for gifted students at the level of the governorates and regions of the Kingdom of Saudi Arabia, creating a specialization in the faculties of education to prepare specialized teachers in it, taking into account the review of syllabi.

Results of the $2^{\text {nd }}$ question: What is the level of self-efficacy of science and mathematics teachers at Najran toward teaching using (STEAM) from their perceptions? To answer this question, means and standard deviations for the level of self-efficacy of science and mathematics teachers at Najran towards teaching using (STEAM) were calculated, and the results presented that the level of self-efficacy among science and mathematics teachers toward teaching using (STEAM) was high $(\mathrm{M}=$ 4.00, STD. Devi $=0.61$ ), in addition to all the scale items. Item (3) "Persuading me in (STEAM) is very hard, as I'm convinced with separation between specializations" ranked first $(\mathrm{M}=4.19$, Std. Devi $=0.85)$ with a high level, followed by item (2) "It is easy for me to teach a scientific approach other than my specialization" $(\mathrm{M}=4.18$, Std. Devi $=0.92$ ) with a high level.

\subsection{Gender Differences}

Results of the $3^{\text {rd }}$ question: Are there any statistically significant differences in the responses of science and mathematics teachers at Najran regarding the application of the (STEAM) when it comes to gender, specialization, school level and teaching experience?

Means and standard deviations of the perceptions of science and mathematics teachers at Najran regarding (STEAM) were calculated. T-test was calculated to reveal the significance of the differences between the means scores, as seen in Table (1). Table (1) shows that there are statistically significant differences at $(\alpha=0.05)$ in the self-efficacy toward (STEAM) due to gender, in favor of males.

Table (1) also showed that there are no statistically significant differences at $(\alpha=0.05)$ in (STEAM) employment methods in pre-university education in light of gender.

\subsection{Specializations Differences}

Furthermore, means and standard deviations for mathematics and science teachers' perceptions toward STEAM in light of specialization were calculated. To reveal the significance of the differences between the means scores, One-Way-ANOVA was calculated. Table (2) shows that there is a difference in the means scores of the science and mathematics teachers' perceptions toward (STEAM) in light of specialization. To reveal the significance of the differences One-Way-ANOVA was calculated as seen in Table (3). Table (3) shows that there are statistically significant differences at $(\alpha=0.05)$ in mathematics and science teachers' beliefs toward (STEAM) in light of specialization on the domain of (STEAM) employment methods in pre-university education, while there were no statistically significant differences in self-efficacy toward STEAM domain. To define the significance differences, Post-Hoc comparisons and Per-Wise using Scheff'e Test was calculated as seen in Table (4). Table (4) shows that there are statistically significant differences at $(\alpha=0.05)$ on (STEAM) employment methods in pre-university education in favor of chemistry, physics, biology and mathematics compared to general science, which means that teachers of chemistry, physics, biology and mathematics are more likely to employ (STEAM) in education.

Table 1. The Results of Gender difference on STEAM

\begin{tabular}{|c|c|c|c|c|c|c|c|}
\hline Factor & Gender & Number & Mean & SD & $\mathrm{t}$-value & $\mathrm{df}$ & Sig \\
\hline \multirow{2}{*}{ invest STEAM approach } & Male & 136 & 4.05 & 0.55 & \multirow{2}{*}{1.150} & \multirow{2}{*}{219} & \multirow{2}{*}{0.251} \\
\hline & Female & 85 & 3.94 & 0.87 & & & \\
\hline \multirow{2}{*}{ Self-Efficacy } & Male & 136 & 4.10 & 0.52 & \multirow{2}{*}{3.277} & \multirow{2}{*}{219} & \multirow{2}{*}{0.001} \\
\hline & Female & 85 & 3.83 & 0.70 & & & \\
\hline
\end{tabular}


Table 2. Mean and Standard Deviation on STEAM approach based on Major

\begin{tabular}{|c|c|c|c|c|}
\hline Factors & Major & Number & Mean & $\mathrm{SD}$ \\
\hline \multirow{6}{*}{ Invest STEAM approach } & Science & 38 & 3.62 & 0.76 \\
\hline & Chemistry & 44 & 4.09 & 0.74 \\
\hline & Physics & 36 & 4.16 & 0.52 \\
\hline & Biology & 33 & 4.23 & 0.54 \\
\hline & Math & 70 & 3.95 & 0.71 \\
\hline & Total & 221 & 4.01 & 0.69 \\
\hline \multirow{6}{*}{ Self-Efficacy } & Science & 38 & 3.76 & 0.83 \\
\hline & Chemistry & 44 & 4.07 & 0.60 \\
\hline & Physics & 36 & 4.16 & 0.47 \\
\hline & Biology & 33 & 4.08 & 0.47 \\
\hline & Math & 70 & 3.93 & 0.60 \\
\hline & Total & 221 & 4.00 & 0.61 \\
\hline
\end{tabular}

Table 3. ANOVA Results on the Study Major

\begin{tabular}{|c|c|c|c|c|c|c|}
\hline Factors & Source & Mean Square & df & Mean & $\mathrm{F}$ & Sig. \\
\hline \multirow{3}{*}{$\begin{array}{c}\text { Invest } \\
\text { STEAM } \\
\text { approach }\end{array}$} & Between group & 7.151 & 4 & 1.788 & \multirow{3}{*}{3.861} & \multirow{3}{*}{0.005} \\
\hline & Within group & 100.019 & 216 & .463 & & \\
\hline & total & 107.170 & 220 & & & \\
\hline \multirow{3}{*}{ Self-efficacy } & Between group & 3.254 & 4 & .814 & \multirow{3}{*}{2.208} & \multirow{3}{*}{0.069} \\
\hline & Within group & 79.594 & 216 & .368 & & \\
\hline & total & 82.848 & 220 & & & \\
\hline
\end{tabular}

Table 4. Scheff'e Test Results on STEAM approach based on Major

\begin{tabular}{|c|c|c|c|c|}
\hline Factors & \multicolumn{2}{|c|}{ Specializations } & \multirow{2}{*}{$\frac{\text { Mean Differences }}{.471^{*}}$} & \multirow{2}{*}{$\frac{\mathrm{SD}}{0.004}$} \\
\hline \multirow{20}{*}{ STEAM Approaches } & Science & Chemistry & & \\
\hline & & Physics & $.539 *$ & 0.002 \\
\hline & & Biology & $.610^{*}$ & 0.001 \\
\hline & & Math & $.328 *$ & 0.029 \\
\hline & Chemistry & Science & $.471 *$ & 0.004 \\
\hline & & Physics & .068 & 0.661 \\
\hline & & Biology & .139 & 0.368 \\
\hline & & Math & .143 & 0.247 \\
\hline & Physics & Science & $.539 *$ & 0.002 \\
\hline & & Chemistry & .068 & 0.661 \\
\hline & & Biology & .071 & 0.675 \\
\hline & & Math & .210 & 0.141 \\
\hline & Biology & Science & $.610^{*}$ & 0.001 \\
\hline & & Chemistry & .139 & 0.368 \\
\hline & & Physics & .071 & 0.675 \\
\hline & & Math & $.282 *$ & 0.049 \\
\hline & Math & Science & $.328^{*}$ & 0.029 \\
\hline & & Chemistry & .143 & 0.247 \\
\hline & & Physics & .210 & 0.141 \\
\hline & & Biology & $.282 *$ & 0.049 \\
\hline
\end{tabular}




\subsection{Education Level}

Additionally, means and standard deviations for mathematics and science teachers' perceptions toward STEAM in light of educational level were calculated. To define the significance of the differences between the means scores, One-Way-ANOVA was calculated as shown in Table (5) and Table (6). Table (5) shows that there are differences between the means scores of mathematics and science teachers' perceptions toward (STEAM) in light of educational level. To reveal the significance of the differences between the means scores, One-Way-ANOVA was calculated as seen in table (6). Table (6) showed that there are no statistically significant differences at $(\alpha=0.05)$ in mathematics and science teachers' perceptions toward STEM in light of educational level on both domains.

\subsection{Work Experiences}

Means and standard deviations for mathematics and science teachers' perceptions toward (STEAM) in light of educational experience were calculated. To define the significance of the differences between the means scores, One-Way-ANOVA was calculated. Table (7) shows that there are differences between the means scores of mathematics and science teachers' perceptions toward (STEAM) in light of educational experience. Table (8) revealed statistically significant differences at $(\alpha=0.05)$ in mathematics and science teachers' perceptions toward (STEAM) in light of educational experience on both domains. To define the significance differences Post-Hoc comparisons and Per-Wise using Scheff'e Test was calculated as seen in Table (9). Table (9) showed that there are statistically significant differences in (STEAM) employment methods in general education and self-efficacy toward (STEAM) between educational experience (less than 5 years) and (5-10 years) in favor of (5-10 years).

Table 5. Mean and Standard Deviation on STEAM approach based on Education Level

\begin{tabular}{|c|c|c|c|c|c|}
\hline Factors & Education level & Number & & Mean & SD \\
\hline \multirow{4}{*}{$\begin{array}{c}\text { Invest STEAM } \\
\text { approach }\end{array}$} & Primary & 42 & & 3.88 & 0.64 \\
\cline { 2 - 6 } & Secondary & 66 & & 3.92 & 0.70 \\
\cline { 2 - 6 } & High & 113 & 4.10 & 0.70 \\
\cline { 2 - 6 } & Total & 221 & 4.01 & 0.69 \\
\cline { 2 - 6 } Self-Efficacy & Science & 42 & 3.84 & 0.63 \\
\cline { 2 - 6 } & Chemistry & 66 & 4.03 & 0.66 \\
\hline
\end{tabular}

Table 6. ANOVA Results on the Education Level

\begin{tabular}{|c|c|c|c|c|c|c|}
\hline Factors & Source & Mean Square & $\mathrm{df}$ & Mean & $\mathrm{F}$ & Sig. \\
\hline \multirow{3}{*}{ Invest STEAM approach } & Between group & 2.175 & 2 & 1.088 & \multirow{3}{*}{2.258} & \multirow{3}{*}{0.107} \\
\hline & Within group & 104.995 & 218 & .482 & & \\
\hline & total & 107.170 & 220 & & & \\
\hline \multirow{3}{*}{ Self-Efficacy } & Between group & 1.231 & 2 & .616 & \multirow{3}{*}{1.644} & \multirow{3}{*}{0.196} \\
\hline & Within group & 81.617 & 218 & .374 & & \\
\hline & total & 82.848 & 220 & & & \\
\hline
\end{tabular}

Table 7. Mean and Standard Deviation on STEAM approach based on Work Experience

\begin{tabular}{|c|c|c|c|c|}
\hline Factors & Major & Number & Mean & SD \\
\hline \multirow{4}{*}{ Invest STEAM approach } & Less than 5 years & 56 & 3.67 & .829 \\
\cline { 2 - 5 } & 5-10 years & 71 & 3.99 & .596 \\
\cline { 2 - 5 } & More than 10 years & 94 & 4.22 & .604 \\
\cline { 2 - 5 } & Total & 221 & 4.01 & .698 \\
\hline \multirow{5}{*}{ Self-Efficacy } & Less than 5 years & 56 & 3.73 & .596 \\
\cline { 2 - 5 } & 5-10 years & 71 & 4.08 & .472 \\
\cline { 2 - 5 } & More than 10 years & 94 & 4.10 & .614 \\
\cline { 2 - 5 } & Total & 221 & 4.00 & \\
\hline
\end{tabular}


Table 8. ANOVA Results on the Work Experience

\begin{tabular}{|c|c|c|c|c|c|c|}
\hline Factors & Source & Mean Square & $\mathrm{df}$ & Mean & $\mathrm{F}$ & Sig. \\
\hline \multirow{3}{*}{ Invest STEAM approach } & Between group & 10.556 & 2 & 5.278 & \multirow{3}{*}{11.909} & \multirow{3}{*}{0.000} \\
\hline & Within group & 96.615 & 218 & .443 & & \\
\hline & total & 107.170 & 220 & & & \\
\hline \multirow{3}{*}{ Self-Efficacy } & Between group & 5.415 & 2 & 2.708 & \multirow{3}{*}{7.623} & \multirow{3}{*}{0.001} \\
\hline & Within group & 77.433 & 218 & .355 & & \\
\hline & total & 82.848 & 220 & & & \\
\hline
\end{tabular}

Table 9. Scheff'e Test Results on STEAM approach based on Work Experience

\begin{tabular}{|c|c|c|c|c|}
\hline Factors & & & Mean Differences & SD \\
\hline \multirow{6}{*}{ STEAM Approaches } & Less than 5 years & $5-10$ years & $.323^{*}$ & 0.027 \\
\hline & & More than 10 years & $.548 *$ & 0.000 \\
\hline & $5-10$ years & Less than 5 years & $.323 *$ & 0.027 \\
\hline & & More than 10 years & .225 & 0.102 \\
\hline & More than 10 years & Less than 5 years & $.548^{*}$ & 0.000 \\
\hline & & $5-10$ years & .225 & 0.102 \\
\hline \multirow{6}{*}{ Self-Efficacy } & Less than 5 years & $5-10$ years & $.347^{*}$ & 0.006 \\
\hline & & More than 10 years & $.368^{*}$ & 0.002 \\
\hline & $5-10$ years & Less than 5 years & $.347^{*}$ & 0.006 \\
\hline & & More than 10 years & .021 & 0.976 \\
\hline & More than 10 years & Less than 5 years & $.368^{*}$ & 0.002 \\
\hline & & 5-10 years & .021 & 0.976 \\
\hline
\end{tabular}

\section{Discussion}

Based on the results of the study, employing (STEAM) in the pre-university education reported high preferences levels by teachers. This result may be attributed to teachers' awareness of the importance of (STEAM) and its applications in education as a process. Teachers are willing to integrate those methods to achieve their educational goals, taking into consideration that they are always looking for a multi-discipline integrative curriculum to achieve meaningful education for their students. (STEAM) provides teachers with practical and intensive applications focusing on learners by integrating mathematics and science actively in the classroom. Furthermore, teachers are interested in using active learning content and adopting suitable instructional procedures when designing projects or developing their lesson plans to present the learning content for students, who in turn can use these instructional media in the classroom to learn mathematics and science. This point reflects that teachers participating in this study are fully aware and knowledgeable about the invaluable opportunities presented by (STEAM) in mathematics and science classrooms. Furthermore, teaching and providing students with untraditional educational activities, in addition to non-conventional school subjects contribute to enriching students' information and deepening their various educational experiences with a new type of educational experiences based on the integrative approach (STEAM) that moves learners from being proactive to active learners in the class. This means that teachers realize the importance of the preparation programs in education reform. The quality of education is closely related to the quality of teachers and their ability to keep pace with the future and the modern educational developments, including the use of integrative approach (STEAM) in education. The result of this study is consistent with those of a previous one [22]. This result is also consistent with the one presented by [21], which showed that the team size and the form of collaboration significantly affect the collaboration and success among teachers in practicing the integration approach of STEAM.

Regarding question two, the result showed that the level of self-efficacy among science and mathematics teachers toward teaching using (STEAM) was high. This feature can be attributed to teachers' awareness of the importance of using (STEAM) in teaching as well as its effective role in improving the teaching and learning process. As far as this approach is concerned, learning is based on problem solving, projects related to life, employing creative methods in research, investigation, analysis and conclusion, where learning occurs through practical application of solving problems in their real context. Using (STEAM) entails following an integrated approach 
of learning rather than mere memorization and rote learning of concepts and facts. This approach coincides with work tasks in the twenty-first century with its modern innovations in which various disciplines overlap to reach the final product or solve the associated problems. The results showed that there were no significant differences between gender levels on the self-efficacy toward (STEAM). This result can be attributed to the training programs launched by the Ministry of Education and the universities, where males may participate in them more often than females, and this may require creating educational curricula based on (STEAM) in teaching that integrates the different specializations. Furthermore, due to the advantages of this approach, the teachers' vision of the importance of (STEAM) in teaching and its role in improving the educational process affects their self-efficacy towards it, and therefore we find them more keen, willing and ready to implement this approach in school education. No significant difference was shown between gender levels in terms of (STEAM) employment methods. This result can be attributed to the fact that the study sample (males and females) has equal levels of knowledge about the importance of (STEAM) in pre-university education and the requirements for employing it in teaching. This illustrates the Saudi Ministry of Education interest in keeping abreast of modern educational developments and emphasizing its implementation in the classes to serve students learning and the future aspirations of Saudi Arabia.

Results also revealed that a significant difference exists between teachers' beliefs toward (STEAM) and their self-efficacy based on their specialization. This may be due to the connections of their specializations to modern scientific issues. Results also revealed that a significant difference exists between teachers' beliefs toward (STEAM) and their self-efficacy based on their education levels and work experience. This can be attributed to the fact that teachers are aware of STEAM importance and its role in transferring education from the traditional method to the modern method that makes education meaningful and makes learners more effective and capable of keeping pace with scientific and technological developments, modern changes, and aware of the modern changes, problems and issues. However, the result of this study is consistent with a previous study [22]. Finally, the results revealed that a significant difference exists between teachers' beliefs toward (STEAM) and their self-efficacy based on their education levels and work experience. This can be attributed to the role of the educational experience in forming the scientific and professional personality of the teacher. Therefore, it is noted that teachers with the longest experience (more than 10 years) possess knowledge, skills and experiences concerning (STEAM) in education; this reflected on their assessments of (STEAM) knowledge, employing it in teaching and defining the appropriate requirements that support the use of the (STEAM) in teaching, and the enhancement of self-efficacy towards (STEAM). The result of this study is consistent with the result of the [24] who found that work experience impacted teachers' beliefs and their self-efficacy towards STEAM.

\section{Conclusions}

The study aims to investigate the applicability of (STEAM) public education from the perspective of science and mathematics teachers at Najran city. In addition, it reveals the impact of gender, specialization, school level and teaching experience variables on teachers' perceptions and their self-efficacy towards applying this approach. The results of the study showed that employing STEAM in the pre-university education reported high preferences levels by teachers as well as their self-efficacy towards STEAM was high. The results of the study showed that there were significant differences on the STEAM approaches and teacher self-efficacy based on the study variables (gender, education level, major and work experience). The importance of employing (STEAM) in education is asserted by responses from the sample of the study. At the same time, researchers would like to draw attention to difficulties involved in implementing this method at the present. For instance, implementing (STEAM) in the school require appropriate engineering design, complete effective use of technology and communications, as well as the presence of experts, specialists and supervisors to develop curricula, teachers' capabilities and the school environment in line with (STEAM). Although previous studies provide important information on the STEAM practices and teachers self-efficacy, much remains to be unknown [22]. Therefore, this study hopefully adds to literature on STEAM education and has border implications beyond Saudi Arabia. Applying STEAM in education would be more successful when it becomes part of the regular curriculum.

\subsection{Limitation and Recommendation}

In light of the findings, the current study recommends the Ministry of Education MOE's adoption of a comprehensive plan in order to activate the methods of employing (STEAM) in public education and determine the best requirements supporting its use in teaching. In addition, the education departments' adoption of strategic plans and training programs ensure science and mathematics teachers' self-efficacy of towards (STEAM). Finally, future studies should conduct comprehensive research addressing science and mathematics teachers' perceptions towards (STEAM) and the problems facing its application in public education. 


\section{REFERENCES}

[1] B. Allina. The development of steam educational policy to promote student creativity and social empowerment". Arts education policy review, 119(2). $2018 \mathrm{http} / / /$ doi.org/10.108 0/10632913.2017.1296392.

[2] J. Maeda. Stem+art=steam. The Steam Journal, 1(1), article 34. 2013. retrieved from https://scholarship.claremont.edu/s team/vol1/iss $1 / 34$ /

[3] B. Tsurusaki, C. Tzou, I. Conner, M. Guthrie. 5th-7th grade girls' conceptions of creativity: implications for steam education. creativity education, (8)2, 255-271. 2017.

[4] N. Graham, I. Brouillette. Using arts integration to make science learning memorable in the upper elementary grades: a quasi-experimental study. Journal for Learning Through the Arts, 12(1). 2016. doi: 10.21977/d912133442.

[5] Y. Kim, N. Park. The development of convergent steam program focused on rube goldberg for improvement of engineer career awareness of elementary school students. in: jeong h., s. obaidat m., yen $\mathrm{n}$., park j. (eds) advances in computer science and its applications, lecture notes in electrical engineering, 279, (pp. 429- 434). Berlin, Heidelberg: Springer. 2014.

[6] C. Anderson. An evaluation of a STEM-based afterschool program for at-risk youth. Unpublished Master Thesis, Portland State University, USA. 2016.

[7] I. Ashour, B. Murad. Self-efficacy among teachers and its relation to teaching quality. Dirasat Studies, 30, 224-236. 2018 .

[8] N. Alsadan, S. Alshamrani. The level of applying integration approach in teaching science in secondary school settings". Arab journal for future education-Arab center for education \& development, 26(116), 330-385. 2019.

[9] H. Koirala, J. Bowman. Preparing middle level preservice teachers to integrate mathematics and science: problems and possibilities. School Science and Mathematics, 145(10), 145-154. 2003.

[10] D. Berlin, A. White. A longitudinal look at attitudes and perceptions related to the integration of mathematics, science, and technology education. school science and mathematics. 112(1), 20-30. 2011.

[11] C. Quigley, D. Herro, F. Jamil. Developing a conceptual model of steam teaching practices. School Science and Mathematics, 117(1-2), 1-12. 2017.

[12] D. Herro, C. Quigley. Exploring teachers' perceptions of steam teaching through professional development: implications for teacher educators. Professional Development in Education, 43(3), 416-438. 2017.

[13] C. Liao. From interdisciplinary to transdisciplinary: an arts-integrated approach to steam education. Art Education, 69(6), 44-49. 2016.

[14] I. Colucci-Gray, P. Burnard, C. Cooke, R. Davies, D. Gray, J. Trowsdale. Reviewing the potential and challenges of developing steam education through creative pedagogies for 21st learning: how can school curricula be broadened towards a more responsive, dynamic, and inclusive form of education? 2017.

[15] D. Henriksen Creating steam with design thinking: beyond stem and arts integration. The STEAM Journal, 3(1), 11. 2017.

[16] E. Perignat, J. Katz-buonincontro. Steam in practice and research: an integrative literature review. Thinking Skills and Creativity, 31, 31-43. 2019.

[17] C. Bomar, S. Lee, I. Lee. Understanding the stem skills gap: a regional perspective. 2017

[18] N. Dejarnette. Implementing steam in the early childhood classroom". European Journal of STEAM Education, 3(3), 18. 2018

[19] M. Conde, C. Fernández, J. Alves, M. Ramos, S. Celis-Tena, J. Gonçalves, F. Peñalvo. Robosteam-a challenge based learning approach for integrating steam and develop computational thinking". Paper presented at the proceedings of the seventh international conference on technological ecosystems for enhancing multiculturality. 2019.

[20] O. Shatunova, T. Anisimova, F. Sabirova, O. Kalimullina. Steam as an innovative educational technology. Journal of Social Studies Education Research, 10(2), 131-144. 2019.

[21] H. Wang, M. Charoenmuang, N., Knobloch, R. Tormoehlen. Defining interdisciplinary collaboration based on high school teachers' beliefs and practices of stem integration using a complex designed system. International Journal of Stem Education, 7 (3), 1-17. 2020.

[22] H. Park, S. Byun, J. Sim, H. Han, Y. Baek. Teachers perceptions and practice of steam education in south Korea. Eurasia Journal of Mathematics, Science \& Technology Education, 12(7), 18739-1753. 2016. doi: 10.12973/eurasia. 2016.1531a.

[23] A. Vidic. Teachers beliefs about STEM education based on realization of the energy as a value project in the Slovenian school system. International Journal of Engineering Education, 33(1), 408-419. 2017.

[24] W. Srikoom. Teachers self-efficacy and beliefs about STEM education. IPST Project. DOI: 10.13140/RG.2.2.25270.528 05 .

[25] J. Ejiwale. Barriers to successful implementation of STEM education. Journal of Education and Learning, 7(2), 63-74. 2013.

[26] C. Chnittka, C. \& Bell, R. Engineering design and conceptual change in science: addressing thermal energy and heat transfer in eighth grade. International Journal of Science Education, 33(13), 1861-1887. 2011.

[27] T. Lowrie, N. Downes, S. Leonard. STEM Education for all young Australians. A Bright spots stem learning huBfoundation paper for SVA, in partnership with Samsung. University of Canberra STEM Education Research Centre. 2018.

[28] B. Sondel, J. Koch, S. Carrier, T. Walkowiak. Toward a theory of teacher education for justice-oriented STEM. 2017.

[29] E. Altan, E. Koroglu. STEM education for disadvantages students: Teachers and student experiences. Turkish Online Journal of Qualitative Inquiry (TOJQI), 10(4), 462-489. DOI: 
10.17569/tojqi.615378. 2019.

[30] M. Jdaitawi. The effect of using problem-based learning upon students emotions towards larning and levels of communication skills in three different disciplines. Croatian Journal of Education, 22(1), 207-240. http://doi.org/10.155 16/cje.v22i13215.

[31] M. Jdaitawi. Social conenctedness, academic, non-acadmeic behaviors related to self-regulation among unievristy stduents in Saudi Arabia. Interantional Education Studies, 8(2), 84-100. 